\title{
A SHORT SURVEY ON EU AGRICULTURE DEVELOPMENTS: CROPPING PATTERNS, PRICES AND POLICY
}

\author{
Iuliana Denisa Radulescu' ${ }^{1}$, Daniela Iorgovan ${ }^{2}$
}

\begin{abstract}
Agriculture forms a fundamental economic branch in the European economy, which has developed particular premises and highlighted significantly transformations in accordance with the Common Agricultural Policy and the new European agricultural model imperatives. The papers' main aim is to design a short survey on EU agriculture development from the perspective of the evolution of cropping pattern, prices and the implications on the sectoral economy. Derived results prove that EU agricultural sector has experienced important and unique transformations regarding the cropping pattern, prices and policy in term of achieving a functional agricultural model.
\end{abstract}

Key words: agriculture, cropping pattern, prices, cereals, CAP.

JEL $^{3}$ : E3, N5, O13, Q1

\section{Introduction}

European agriculture, under the influence of the exigencies of the common agricultural policy (CAP) has registered significant transformations, both from the perspective of development paradigms, but especially of sectoral evolutions. Agriculture has become for the EU an important economic sector with multiple values and with significant implications on rural communities, economic structures as a whole, but also in the mechanism and evolution of prices. Analysing the European agricultural sector, we can also observe the evolution of the European construction as a whole, starting from the simple fact that the common agricultural policy was also the first common policy developed at the level of the European community.

Without neglecting the importance of other economic domains in the European economy as a whole, agriculture as an independent economic sector reflects the steps of a massive optimization of production structures by reorienting capital, human

1 Radulescu Iuliana Denisa, Ph.D. student, The Bucharest University of Economic Studies, Doctoral School II, Mihail Moxa Street no. 5-7, Bucharest, Romania, Phone: +40 769323710 , E-mail: dennisaradulescu@gmail.com

2 Daniela Iorgovan, B.A. student, Faculty of Economic Science, University of "Constantin Brâncuși” Târgu-Jiu, Tineretului Street no. 4, Targu Jiu, Romania, Phone:+40 766641018 , E-mail: iorgovandaniela@yahoo.com

3 Article info: Review Article, Received: $8^{\text {th }}$ July 2020, Accepted: $20^{\text {th }}$ July 2020. 
and material flows to a vital sector that is still experiencing sustainable measures of sectoral reform. Agriculture is in itself the only economic sector capable of satisfying the food needs of the population, the biodiversity of rural areas, and not only, but also essential public goods in terms of environmental protection, water resources, soil and protection of the natural environment. Agriculture is not limited to food production and ensuring food security and safety but also to the paradigm and management of water resources, soil, agricultural land, in general to traditional agricultural resources, being also an economic domain that ensures the occupation of an important rural labour forces.

At the same time, agriculture contributes to the supply of public goods, as noted (Abler, 2004), public goods generated by agriculture are not directly related to the actual production, but rather to land use and agricultural structures capable of capitalizing on them.

As indicated in literature (Frandsen et al., 2006; Mishra, El Osta, 2008; Trouvé, Berriet Solliec, 2010; Andrei, Darvasi, 2012), agriculture and CAP still cause synergistic effects in the European economy. Faced with numerous challenges determined, not only by the effect of globalization of trade relations, but also by the specific thresholds of profitability and the questionable level of specific competitiveness, European agriculture is still experiencing important paradigm shifts and complementarities.

Thus, Matthews (2015) referring to CAP, argues that it has long been criticized for its harmful effects on agriculture in developing countries, as it is the main cause of deepening discrepancies and gaps between agricultural sectors. It is happened in the newer countries of EU.

Re-nationalization trends manifested on the European unique market contribute to deepening the divergence of prices and specific markets. Factors such as political uncertainty, climate change, and low sectoral efficiency contribute significantly to large price fluctuations in agricultural markets, farmers being vulnerable to these problems. Farmers' incomes are affected by the volatile prices of raw materials and food produced by them, further amplifying the need for harmonization of measures in agriculture.

European agriculture develops important advantages for contemporary society through its multifunctional character, from the development and implementation of an efficient and widely diversified agri-food chain, by providing food and raw materials for industry at convenient and competitive prices to the sustainability of European farmers' incomes. 
Agriculture thus determines and amplifies a multifunctional framework at European level that is not limited not only to economic production and ensuring local economic growth, but also to mobilize available resources in rural areas and capitalize on them at a higher level and ensure proper development of rural communities.

The diversity of agricultural policy measures often determines the degree of efficiency and sectoral compatibility. Farmers must ensure a sufficient level of agricultural production to enrich the European market and prevent dependence on food imports and expand competitiveness. However, the degree of performance of European agriculture is closely dependent on the production structure, the quality and typology of the lands, the degree of technological equipment that gives an uneven character to the agricultural policy, although, it is wished to be a common and harmonizing one in this sector.

In the long run, the common agricultural policy will undergo multiple and farreaching transformations, sometimes even forced, determined by the technological revolution that agriculture is facing in the $21^{\text {st }}$ century, demographic changes in rural areas, migratory flow or climate change, as argued in recent specialty studies such as (Majewski, Malak Rawlikowska, 2018; Kiryluk Dryjska, Baer Nawrocka, 2019; Malang, Holzinger, 2020).

As highlighted by Navarro and López Bao (2019), the Common Agricultural Policy (CAP) is one of the most important, impactful and expensive European sectoral policies with a budget of 362.8 billion EUR in the period 2014-2020, which further deepens the need for results from it. The evolution of agricultural production structures but also of cropping pattern highlights, on the one hand, both an extensive process of adaptation to the specific market requirements and the need for competitiveness, and on the other hand, includes the effects of financial measures adopted under the CAP and reorientation towards new agricultural paradigm. The Common Agricultural Policy has defined and continues to build a community agricultural model, (Chivu, 2002; Andrei, Ungureanu, 2014; Andrei et al., 2015; Roederer Rynning, 2019), with significant implications on the structures of production, how to use and mobilize resources in rural communities.

In order to understand the complex character of European agriculture and the effects of CAP on this sector, in this paper we will analyse, but at a summarized level, some of the specific indicators relevant to the field, through which some of the significant changes that European agriculture has faced will be highlighted. From this perspective we decided to structure the paper in two parts, each of them being dedicated to an essential aspect in understanding the subject under analysis in this paper. At the same time, we established as objectives of the paper a short analysis 
of the main transformations of European agricultural policy from the perspective of several indicators, such as (utilized agricultural area, arable land by crop categories, production share of cereals by main producing EU Member States, deflated price indices for cereals) taking into account some countries of the Visegrad group, to which we added Bulgaria and Romania. In order to fulfil the research aims and scope, it was used the descriptive analysis highlighting the major changes and transformations of the EU agricultural economy. In this context it was used the Eurostat datasets.

\section{Analysis of cropping patterns in some EU countries}

The superior capitalization of the agricultural potential implies an efficient use of the agricultural resources including the agricultural area. Over time, the degree of capital endowment and the availability of agricultural resources have been determining factors in shaping the forms of agricultural exploitation. The distribution of land use forms varies significantly throughout the EU, as it can be seen in Figure1. and Table 1.

Figure 1. Utilized agricultural area by Member States (EU-28, in 2016, in \%)

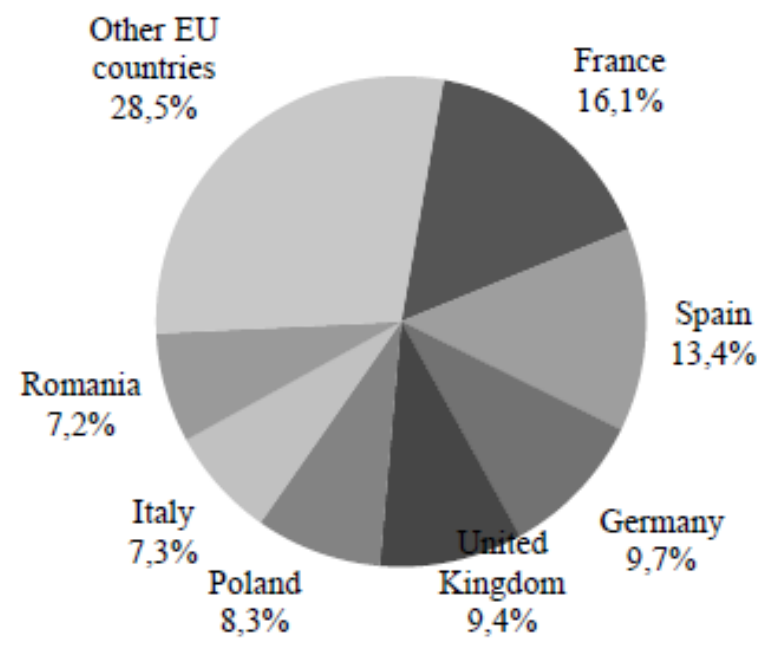

Source: Eurostat, 2019a.

From Figure 1. it can be noticed that France and Spain concentrate significant values of the utilized agricultural area, while UK and Germany have approximately equal values in terms of this indicator, around 9\%, while in Romania and Italy the values are around $7 \%$. However, for a detailed picture of the distribution of agricultural area by land cover types and of the changes that occurred over time, Table 1 presents some of the main forms of agricultural area by land cover types, in 2005 and 2016, respectively. 
As can be seen in table, the distribution of the main types of agricultural land cover (arable land, permanent grassland, and permanent crops) varied greatly between Member States during the observed period. Although, at EU level, there is an increase from 125,534 thousand hectares in 2005 to 172,967 thousand hectares in 2016, in the case of Romania the situation is diametrically opposed, registering a decrease from 13,907 thousand hectares in 2005 to 12,503 thousand hectares in 2016. Figure 2 . shows the percentage distribution of arable land by crop categories in some EU-28 in 2016.

Table 1. Utilized agricultural area by land cover types (in 2005 and 2016, in 000 ha)

\begin{tabular}{|c|c|c|c|c|c|c|c|c|}
\hline \multirow[t]{2}{*}{ Country } & \multicolumn{2}{|c|}{ Total } & \multicolumn{2}{|c|}{ Arable land } & \multicolumn{2}{|c|}{$\begin{array}{l}\text { Permanent grassland } \\
\text { and meadow }\end{array}$} & \multicolumn{2}{|c|}{ Permanent crops } \\
\hline & 2005 & 2016 & 2005 & 2016 & 2005 & 2016 & 2005 & 2016 \\
\hline $\mathbf{E U}$ & 125.534 & 172.967 & 80.550 & 103.081 & 35.726 & 59.136 & 8.877 & 10.504 \\
\hline Bulgaria & 2.729 & 4.469 & 2.523 & 3.219 & 107 & 1.147 & 81 & 98 \\
\hline Estonia & 829 & 995 & 584 & 687 & 237 & 304 & 3 & 3 \\
\hline Latvia & 1.702 & 1.931 & 1.076 & 1.285 & 599 & 634 & 25 & 8 \\
\hline Lithuania & 2.792 & 2.925 & 1.873 & 2.130 & 891 & 769 & 28 & 26 \\
\hline Hungary & 4.267 & 4.671 & 3.607 & 3.822 & 469 & 690 & 167 & 150 \\
\hline Poland & 14.755 & 14.406 & 11.308 & 10.806 & 3.020 & 3.176 & 330 & 393 \\
\hline Romania & 13.907 & 12.503 & 8.867 & 7.813 & 4.530 & 4.245 & 339 & 301 \\
\hline Slovenia & 485 & 488 & 174 & 175 & 282 & 285 & 27 & 27 \\
\hline Slovakia & 1.879 & 1.890 & 1.319 & 1.347 & 530 & 525 & 26 & 18 \\
\hline
\end{tabular}

Source: Authors' selection based on Eurostat, 2019a.

Starting from the premise that cropping patterns are strongly correlated and related to the way in which natural resources are used and especially managed, thus it is identified the way in which management practices are affected in the capitalization process of resources. Considering the data presented in Figures 1. and 2., and Table 1., it could be said that there is a certain concentration of cultures and their clustering on certain groups of states. In the case of the analysed states, the distribution of arable land by crop categories also highlights the predilection towards certain cultures that have become classics in cropping pattern.

However, it should be stated that the realities described in Figure 2. are the results of land use developed over a long period of time and that it models, as highlighted in specialized studies (Hodge et al., 2015; Andersen, 2017; Fanelli, 2019), agricultural landscapes, defined by agricultural practices and specializations, but also by water availability, temperature or soil quality, or as appropriate by agricultural policies, traditions, size of rural communities, the welfare of farmers, which influences very often the specific production decision. Figure 2. shows, as previously mentioned, arable land by crop categories in some EU countries in 2016 (in \%). 
Figure 2. Arable land by crop categories in EU-28 (in 2016, in \%)

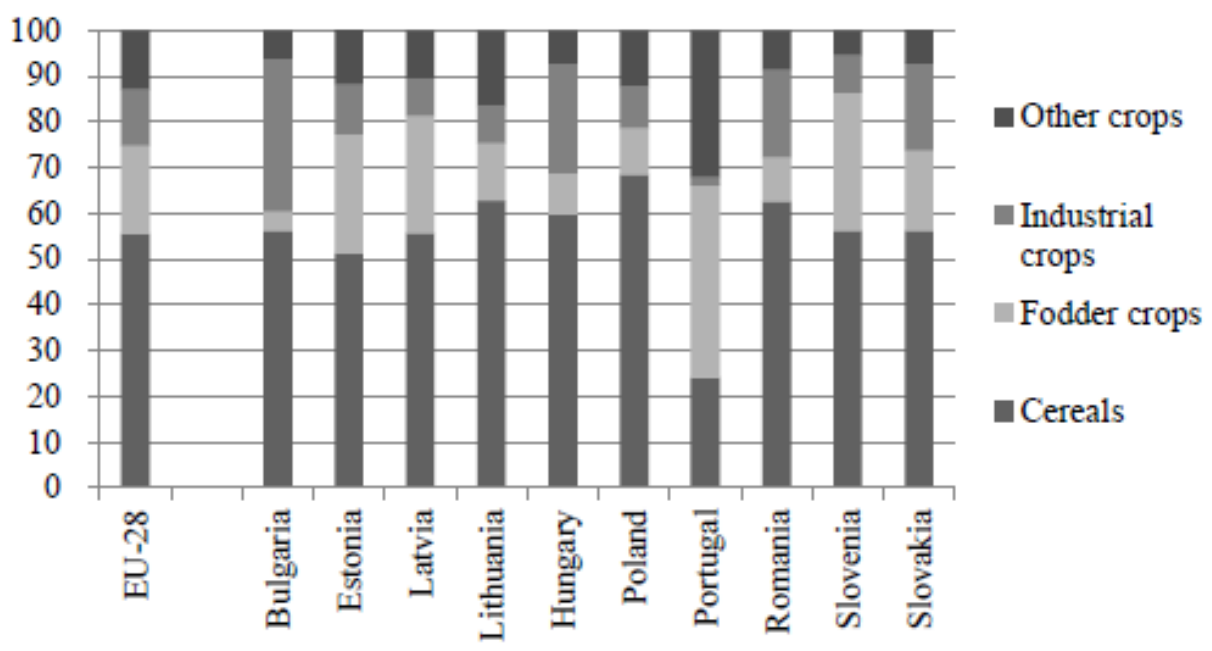

Source: Authors selection based on Eurostat, 2019a.

It can be seen that cereals are preferred in countries such as Romania, Bulgaria, Lithuania and Slovenia, while industrial crops in Portugal. As was highlighted, industrial crops took around $33 \%$ of the arable land in Bulgaria while the next highest share of industrial crops $(23.7 \%)$ is recorded in Hungary, while in Romania and Slovakia, the share of industrial crops in the arable land was between $19 \%-20 \%$ in 2016 (Eurostat, 2019a).

\section{Analysis of the cereal production and price evolution}

Starting from the information regarding cropping pattern in the previous section of the paper, the production of cereals is analysed by main producing in some EU Member States and the price evolution in order to identify the possible paradigm changes and the influences determined by it. Cereals are for most of the observed states the main culture of agricultural lands, around which a large part of agricultural holdings grow. In this context it will be analysed: production share of cereals by main producing EU Member States and Deflated price indices for cereals. Figure 3. shows the production of cereals by main producing EU Member States in 2018. 
Figure 3. Production of cereals by main producing EU Member States (in 2018)

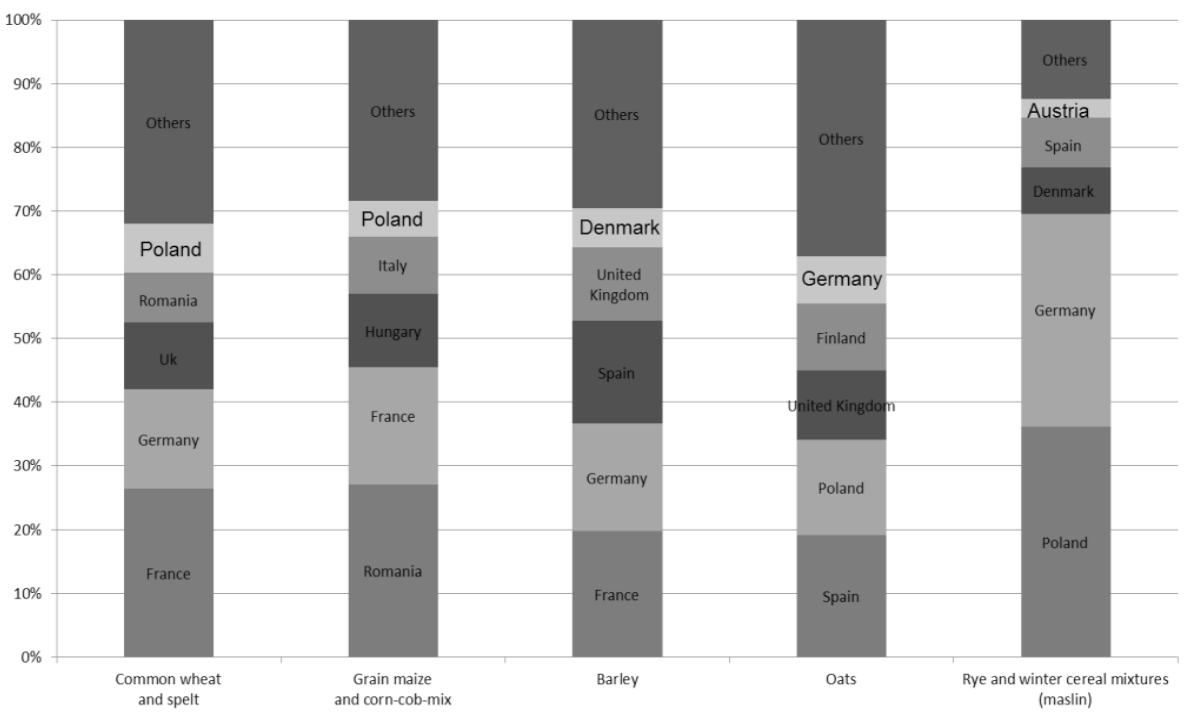

Source: Authors' selection based on Eurostat, 2019a.

Analysing the data from Figure 3., we can see a confirmation of the cropping pattern of agricultural lands in the case of the analysed fields, these concentrating significant grain productions at EU level. Thus, according to Eurostat, production of cereals in the EU in 2018 was about 295.1 million tons $(11.3 \%$ of global production), which represents 14.9 million tons less than in 2017 , or recording a sharp fall of $4.8 \%$ (Eurostat, 2019b)

Decreasing cereal production at European level, although it can be attributed to a wide range of factors, such as drought intensity, lack of labour or the reorientation of farmers to more efficient and economically profitable crops, means a reorientation of the European agricultural paradigm. If the heavily capitalized states, and wellendowed in terms of the degree of capitalization of agriculture, have opted for large field crops, the ex-socialist states register declines in agricultural production. The immediate effect can be noticed in the evolution of agricultural prices. Figure 4 . shows the deflated price indices for cereals (during the period 2010-2018). 
Figure 4. Deflated price indices for cereals, period 2010-2018 (in \% of EU-28 total cereals production)

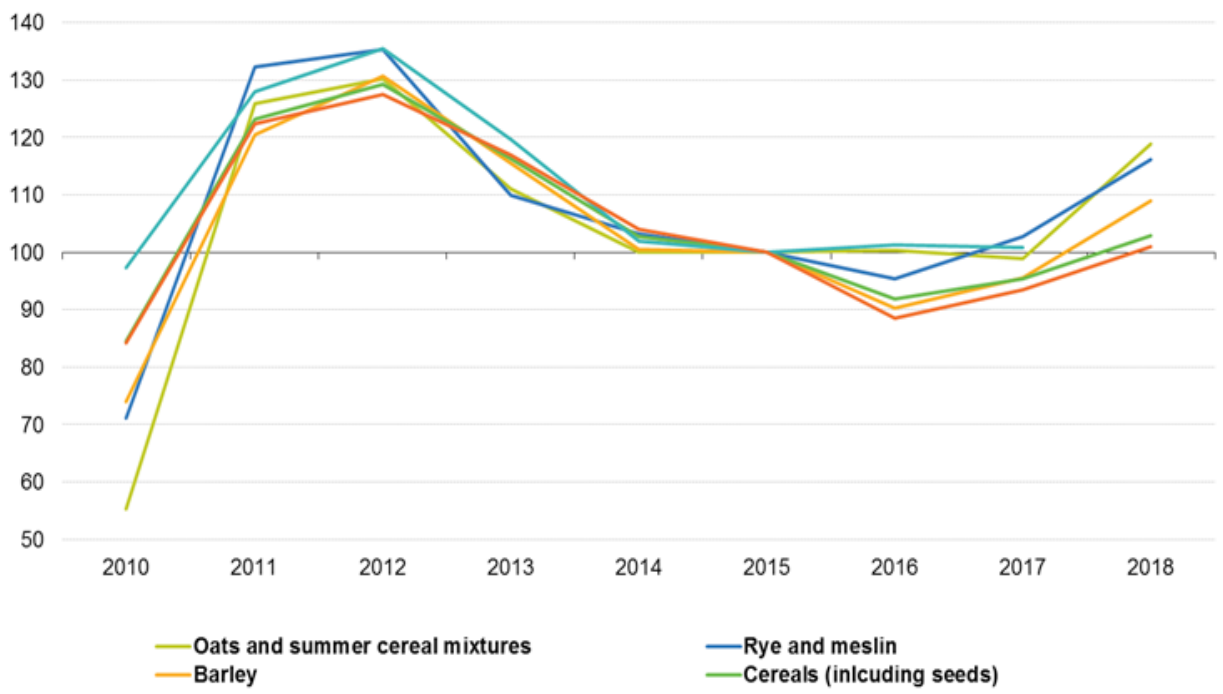

Source: Authors' calculation based on Eurostat, 2019b.

From Figure 4. one can easily notice a high degree of volatility of the price indices for cereals, 2010-2018. The evolution of this indicator means not only the instability of these prices but also a certain migration of farmers to other economically efficient crops. It can be seen that the European agricultural sector is going through a period of readjustment and adaptation to the new demands on competitiveness and economic efficiency against the background of massive challenges generated by global economic adjustments. Under these conditions, the production of cereals by main producing and deflated price indices for cereals can be alert indicators regarding the global structural changes of European agriculture.

CAP can define in these conditions the orientation of farmers towards large field crops, as well as cereals, under the influence of the mechanism of subsidization and global support of agriculture. The adjustment of agricultural prices in the case of cereals is somehow dependent on the system of agricultural subsidies mobilized through this sectoral policy.

\section{Conclusion}

The development and evolution of European agriculture has been achieved under the impact and significant influence of the Common Agricultural Policy which has 
imposed, most of the time, the ways of superior capitalization of land cultivation. The development of agricultural policies at the level of European states must take into account the foundation on the diversity of agricultural models already developed at the level of each European state and must take into account the diversity of objectives to be achieved. However, starting from the reality that CAP is a tool of direct intervention with significant influence on farmers' behaviour, it must respond effectively to market turmoil.

Analysing cropping pattern, prices and the implications on the sectoral economy, we can conclude the following more significant aspects:

- The first brings to the fore the need to head agricultural production towards the market and capitalize on the already existing potentials at national level;

- The second aspect considered implies the deepening of the structural analysis of the community agricultural sector and the tendencies to adapt to the global challenges;

- The third observation brings, however, into discussion the need to build a solid and functional agricultural paradigm that promotes the optimization of agricultural production structures and their harmonization with the interests of rural communities.

As a final summary conclusion, it can be shown up that the tendencies of renationalization and internalization of agricultural incomes manifested on the EU unique market contribute even more to the deepening of social disparities at rural level but also an increasing of the divergence of prices and profile markets.

\section{References}

1. Abler, D. G. (2004). Multifunctionality, agricultural policy, and environmental policy. Agricultural and Resource Economics Review, 33(1):8-17.

2. Andersen, E. (2017). The farming system component of European agricultural landscapes. European Journal of Agronomy, 82(B):282-291.

3. Andrei, J. V., Darvasi, D. (2012). Perspectives and challenges in financing the new Common Agricultural Policy, a new paradigm. Journal of Food, Agriculture \& Environment, 10(1/2):904-907.

4. Andrei, J. V., Dusmanescu, D., Mieila, M. (2015). The influences of the cultural models on agricultural production structures in Romania and some EU-28 countries: A perspective. Economics of Agriculture, 62(2):293-307. 
5. Andrei, V. J., Ungureanu, A. (2014). The importance of economic structure evolution in achieving performance-from agrarian economy to competitiveness in Romanian economy. Economics of agriculture, 61(4):945-957.

6. Chivu, L. (2002). Competitivitatea în agricultură: Analize şi comparații europene. Academia Română, CIDE, Bucharest, Romania, p. 52.

7. Eurostat (2019a). Agri-environmental indicator - cropping patterns, webportal of Eurostat, Luxembourg, retrieved at: https://ec.europa.eu/eurostat/ statistics-explained/index.php?title=Agri-environmental indicator - cropping patterns\#Analysis of cropping_patterns at country_level, $11^{\text {th }}$ April 2020.

8. Eurostat (2019b). Agricultural production - crops, web-portal of Eurostat, Luxembourg, retrieved at: https://ec.europa.eu/eurostat/statistics-explained/index. php?title=Agricultural production - crops\#Cereals, $11^{\text {th }}$ April 2020.

9. Fanelli, R. M. (2019). The (un)sustainability of the land use practices and agricultural production in EU countries. International Journal of Environmental Studies, 76(2):273-294.

10.Frandsen, S. E., Gersfelt, B., Jensen, H. G. (2006). The impacts of redesigning European agricultural support. In: Doi, M. (Edt.) Computable General Equilibrium Approaches in Urban and Regional Policy Studies, World Scientific Publishing Co., Singapore, pp. 231-267.

11.Hodge, I., Hauck, J., Bonn, A. (2015). The alignment of agricultural and nature conservation policies in the European Union. Conservation Biology, 29(4):9961005 .

12.Kiryluk Dryjska, E., Baer Nawrocka, A. (2019). Reforms of the Common Agricultural Policy of the EU: Expected results and their social acceptance. Journal of Policy Modeling, 41(4):607-622.

13.Majewski, E., Malak Rawlikowska, A. (2018). Scenarios of the Common Agricultural Policy after 2020. Problems of Agricultural Economics, 1(354):9-37.

14.Malang, T., Holzinger, K. (2020). The political economy of differentiated integration: The case of common agricultural policy. The Review of International Organizations, 15:1-26.

15.Matthews, A. (2015). The Common Agricultural Policy and development. In: McMahon, J., Cardwell, M. (Eds.), Research handbook on EU agriculture law, pp. 485-504, Edward Elgar Publishing, Cheltenham, UK.

16.Mishra, A. K., El Osta, H. S. (2008). Effect of agricultural policy on succession decisions of farm households. Review of Economics of the Household, 6(3):285307. 
17.Navarro, A., López Bao, J. V. (2019). EU agricultural policy still not green. Nature Sustainability, 2(11):990.

18.RoedererRynning, C.(2019). The Common AgriculturalPolicy: Acase ofembedded liberalism. In: Thompson, W., (Edt.), Oxford Research Encyclopedia of Politics, Oxford University Press, UK, doi:10.1093/acrefore/9780190228637.013.1032.

19.Trouvé, A., Berriet Solliec, M. (2010). Regionalization in European agricultural policy: Institutional actualities, issues and prospects. Regional Studies, 44(8):10051017. 